\title{
PERSPEKTIF BELAJAR SEBAGAI LANDASAN PSIKOLOGIS DALAM PENGEMBANGAN MEDIA DAN TEKNOLOGI PEMBELAJARAN
}

\author{
Sitti Fatimah S. Sirate ${ }^{1}$, Muhammad Yaumi ${ }^{2}$ \\ 1Sekolah Tinggi Ilmu Pendidikan dan Keguruan YPUP Makassar \\ ${ }^{1}$ Kampus: Jalan Andi Tonro No. 17, Pa'baeng-Baeng, Makassar \\ ${ }^{2}$ Fakultas Tarbiyah dan Keguruan UIN Alauddin Makassar \\ ${ }^{2}$ Kampus II: Jalan H. M Yasin Limpo No. 36 Samata-Gowa \\ Email: fatimahsirate@yahoo.com ${ }^{1}$, muhammad.yaumi@uin-alauddin.ac.id ${ }^{2}$
}

\begin{abstract}
Abstrak:
Kajian ini bertujuan untuk mendeskripsikan konsep dasar belajar dan menguraikan berbagai perspektif belajar sebagai landasan psikologis dalam pengembangan media dan teknologi pembelajaran. Hasil kajian menunjukkan bahwa belajar merupakan perubahan kemampuan manusia yang relatif permanen sebagai akibat dari pengalaman dan interaksi dengan lingkungan. Terdapat tiga perspektif belajar sebagai landasan dalam pengembangan media dan teknologi pembelajaran. Perspektif behavioris menekankan pada pengembangan media dan teknologi untuk pengelolaan dan penyajian sumber belajar, serta penyelesaian tugas mandiri melalui CAL. Perspektif kognitif fokus pada pemanfaatan piranti lunak untuk pengaktifan proses memori dalam belajar. Perspektif konstruktivis perpijak pada integrasi social media untuk memfasilitasi interaksi sosial secara kolaboratif dan membangun makna melalui aktivitas sesuai dunia nyata.
\end{abstract}

\begin{abstract}
:
This study aims at describing the basic concepts of learning and elaborating various learning perspectives as a psychological foundation in the development of instructional media and technology. The results show that learning is a relative permanent change in human capabilities as a result of experience and interaction with the environment. There are three learning perspectives as the basis for instructional media and technologydevelopment. Behavioral perspectives emphasize media and technology development for managing and presentinginstructional resources, as well as the completion of independent tasks through CAL. The cognitive perspectivesfocus on the utilization of software for the activation of memory processes in learning. Constructivist perspectivescentralize on social media integration to facilitate collaborative social interaction and construct meaning through real world activity.
\end{abstract}

Kata kunci:

Perspektif Belajar, Landasan Psikologi, Media dan Teknologi Pembelajaran

SALAH satu landasan penting dalam pengembangan media dan teknologi pembelajaran adalah teori belajar. Semua produk media dan teknologi menjadi kurang relevan dengan kebutuhan peserta didik ketika tidak melibatkan pemahaman komprehensif terhadap aspek-aspek belajar dan pembelajaran (Bates \& Poole, 2003). Bahkan setiap memproduksi bahan ajar, media, dan teknologi pembelajaran harus menelaah teori-teori mutakhir tentang belajar, pengembangan, media, dan teknologi (Peppler \& Kafai, 2007). 
Sebelum membahas beberapa perspektif belajar sebagai landasan psikologis dalam pengembangan media dan teknologi pembelajaran, kiranya perlu memberikan penajaman konseptentang perspektif dalam belajar secara terpisah. Secara umum, perspektif dimaknai sebagai cara memandang sesuatu (Lever-Duffy, McDonald, \& Mizell, 2015). Perspektif juga dimaknai sebagai pandangan ataupenekanan yang lebih umum dan luas (Hutchison \& Charlesworth, 2003). Perspektif (perspective)adalah "A way of perceiving the world flows from a value position. The perspective will influence choice of theory and model" (Payne, 1998: 2). Definisi ini menekankan bahwa perspektif merupakan cara untuk memahami dunia yang terbangun dari posisi nilai. Perspektif akan memengaruhi pilihan teori dan model. Perspektif hanyalah cara untuk melihat dunia (Mooney, Knox, \& Schacht, 2014).

Dalam ilmu geometri (ilmu ukur), perspektif dipahami sebagai bentuk geometri halus yang melukiskan gambar dan objek (Storey, 2006). Adapun makna perspektif dalam kaitannya dengan belajar merupakan cara pandang belajar berdasarkan paham, keyakinan, dan sudut pandang. Dengan demikian, orang yang memiliki disiplin ilmu yang berbeda tentu mempunyai pandangan yang berbeda tentang sesuatu tergantung dari sisi mana dia melihat. Belajar merupakan kegiatan kompleks yang dapat dijelaskan secara berbeda jika dilihat dari berbagai perspektif teori yang berbeda. Seseorang mungkin akan setuju dengan teori belajar tertentu ketika dia berada pada sudut pandang yang sama.

Belajar dapat dijelaskan secara umum dan khusus berdasarkan perspektif masing-masing ilmuan. Pada bagian ini, belajar didefinisikan secara umum, kemudian dikaji melalui perspektif yang berbeda-beda berdasarkan teori belajar. Secara umum, belajar dipahami sebagai persisting change in capability resulting from the learner's experience and interaction with the world (Driscoll \& Driscoll, 2005: 11). Belajar dalam hal ini dianggap sebagai perubahan kemampuan yang dihasilkan dari pengalamandan interaksi dengan dunia. Menurut Ibnu Khaldun dalam Yaumi (2016) belajar juga dipandang sebagai pemerolehan kebiasaan (malaka/habitus) yang dihasilkan dari tindakan yang berulang-ulang hingga sampai pada bentuk akhir. Kebiasaan dibentuk secara bertahap dari warna jiwa.

Belajar juga dipahami sebagai perubahan yang relatif permanen dalam pengetahuan seseorang berdasarkan pengalaman yang diperolehnya (Clark \& Mayer, 2008). Belajar adalah perubahan abadi dalam perilaku, atau kapasitas untuk berperilaku dalam suatu kebiasaan yang dihasilkan dari praktik atau bentuk lain dari pengalaman (Zimmerman \& Schunk, 2008). Menurut Gagne, Wager, Golas, Keller, \& Russell (2005: 2) learning is a change in human disposition or capability that persists over a period of time and is not simply ascribable to processes of growth. Maksudnya belajar merupakan perubahan dalam watak atau kemampuan manusia yang bertahan selama periode waktu dan bukan dipandang sebagai perubahan dalam proses pertumbuhan fisik.

Dengan demikian, belajar merupakan perubahan kemampuan manusia yang relatif permanen sebagai akibat dari pengalaman dan interaksi dengan lingkungan. Perubahan yang dimaksud adalah perubahan internal yang mencakup pengetahuan, 
sikap, mental, dan keterampilan. Perubahan yang dimaksud terjadi dari dalam diri peserta didik yang belajar termasuk pikiran, perasaan, dan jiwa yang terbentuk melalui pengalaman.

Untuk membahas secara rinci tentang belajar, di bawah ini dijelaskan tiga pandangan belajar yang melihat dari tiga perspektif, yaitu behavioris, kognitivis, dan konstruktivis. Pembahasan difokuskan pada lima aspek; (1) definisi belajar, (2) proses belajar, (1) peran pendidik, (4) peran peserta didik, dan (5) peran teknologi dan media.

\section{PEMBAHASAN}

\section{Perspektif Behavioris}

Behaviorisme adalah pandangan yang mengatakan bahwa perilaku harus dijelaskan melalui pengalaman yang dapat diamati, bukan dengan proses mental (Santrock, 2011). Perilaku di sini adalah sesuatu yang dilakukan yang dapat dilihat dan disaksikan secara langsung. Seorang anak merekam suara dalam mengerjakan tugas untuk media audio, memasang poster untuk media visual, dan menyuting gedung sekolah untuk media video, adalah suatu bentuk perilaku yang dapat diamati.

Sedangkan pemikiran anak tentang cara membuat media audio, visual, dan video, perasaan guru ketika melihat tugas yang dilakukan oleh anak, dan motivasi anak dalam mengontrol perilakunya merupakan bentuk proses mental yang tidak dapat diamati secara langsung. Proses mental adalah pikiran, perasaan, dan motif yang dialami seseorang tetapi tidak dapat dilihat orang lain (Santrock, 2011: 266).

\section{Definisi Belajar}

Dalam pandangan behavioris, belajar adalah perubahan perilaku sebagai akibat dari interaksi antara stimulus dan respon (Gredler, 2009). Definisi ini menekankan pada perubahan perilaku yang dapat diamati dari hasil hubungan timbal balik antara pendidik sebagai pemberi stimulus dan peserta didik sebagai perespon tindakan stimulus yang diberikan. Menurut kaum behavioris, belajar digambarkan sebagai suatu perubahan dalam probabilitas bahwa seseorang akan berperilaku dengan cara yang khusus pada situasi yang khusus pula (Newby, Stepich, Russell, \& Lehman, 2011: 27).

\section{Proses Belajar}

Untuk melihat proses belajar dari perspektif behavioris dapat diamati melalui tiga pendekatan, yaitu classical conditioning dari Ivan Petrovich Pavlov, Connectionism dari Edward Lee Thorndike, dan operant conditioning dari Burrhus Frederick Skinner. Pertama, teori classical conditioning didasarkan atas reaksi sistem tak terkontrol di dalam diri seseorang dan reaksi emosional yang dikontrol oleh sistem syaraf serta gerak reflek setelah menerima stimulus dari luar (Woolfolk, 2009). Suatu hal yang terpenting dari teori ini adalah tentang metode yang digunakan dalam proses belajar dan hasil-hasil yang diperolehnya.

Kedua, teori connectionism, menekankan pada jaringan asosiasi atau hubungan antara stimulus dan respon yang kemudian disebut $S-R$ bond theory. Dalam hubungan 
antara stimulus dan respon ini dipengaruhi oleh beberapa faktor, sehingga Thorndike merumuskan tiga hukum belajar, yakni; 1) law of readiness, yaitu bahwa belajar akan terjadi bila ada kesiapan pada diri individu, 2) law of excercise, yaitu bahwa hubungan antara stimulus dan respon dalam proses belajar akan diperkuat atau diperlemah oleh tingkat intensitas dan durasi dari pengulangan hubungan atau latihan yang dilakukan, (3) law of effect, yaitu bahwa hubungan antara stimulus dan respon akan semakin kuat apabila suatu respon menghasilkan efek yang menyenangkan. Sebaliknya, apabila respon kurang menyenangkan, maka hubungan antara stimulus dan respon akan melemah(Eggen \& Kauchak, 2007).

Ketiga, teori operant conditioning, mengatakan bahwa perilaku dalam proses belajar terbentuk oleh sejauh mana konsekuensi yang ditimbulkan. Jika konsekuensinya menyenangkan, maka akan terjadi positive reinforcement atau reward akan membuat perilaku yang sama terulang lagi, sebaliknya apabila konsekuensinya tidak menyenangkan yaitu negative reinforcement atau punishment akan membuat perilaku dihindari (Brush, 2014). Dengan demikian, pembelajaran yang dapat memberikan hadiah bagi peserta didik yang telah mencapai target sesuai yang diinginkan dan memberikan hukuman bagi yang tidak mampu menghasilkan sesuatu yang terbaik akan memberikan dampak besar dalam perubahan perilaku anak yang sedang belajar. Walaupun teori ini masih menyimpan tanda tanya dalam berbagai persoalan pembelajaran, namun teori ini telah banyak meletakkan fondasi yang kuat bagi perkembangan teoriteori belajar kontemporer.

Singkatnya, proses belajar dari perspektif behavioris dapat dijelaskan melalui model $\mathrm{A} \rightarrow \mathrm{B} \rightarrow \mathrm{C}$ seperti: lingkungan menyajikan pendahuluan atau antecedent (A) yang mendorong perilaku (B) yang diikuti dengan konsekuensi (C), kemudian menunjukkan apakah perilaku akan berubah lagi. Belajar terjadi jika peserta didik berperilaku konsisten sesuai dengan cara yang diinginkan dalam merespon lingkungan (pendahuluan). Dengan kata lain, belajar itu terjadi jika A secara konsisten mendorong B yang menghasilkan C. Misalnya, seorang instruktur mengemudi mengajarkan muridnya bagaimana cara berparkir paralel. Secara bertahap, instruktur meminta muridnya untuk mencari ruang yang lebih besar untuk bisa masuk di antara dua mobil lain yang sedang diparkir (A), setelah mengetahui cara memarkir kendaraan melalui ruang yang lebih besar, instruktur memberi instruksi untuk mencari ruang lain yang lebih sempit yang hanya menyediakan ruang sedikit di antara dua mobil lain yang sedang diparkir (B), kemudian menunjukkan apakah terjadi perubahan perilaku dalam memarkir kendaraan tersebut atau tidak.

\section{Peran Pendidik}

Dalam kerangka modelA $\rightarrow \mathrm{B} \rightarrow \mathrm{C}$ seperti dijelaskan di atas, di mana belajar dipengaruhi oleh lingkungan eksternal, maka peran guru, dosen, atau instruktur sebagai pendidik adalah menyediakan pembelajaran yang diarahkan pada bagaimana menciptakan kondisi lingkungan belajar yang nyaman (A) untuk membantu peserta didik belajar (B) sehingga dapat menciptakaan perubahan perilaku (C) sebagai akibat 
dari interaksinya dengan lingkungan belajar (Ormrod, 2011). Tugas pendidik adalah a. Merumuskan tujuan pembelajaran berdasarkan karakteristik peserta didik.

b. Mengarahkan perilaku peserta didik dengan menggunakan petunjuk-petunjuk atau prosedur kerja.

c. Memberi penguatan perilaku jika telah mengarah pada tindakan yang sesuai dengan yang diharapkan. Penguatan yang diberikan berupa nilai yang tinggi, sertifikat penghargaan, atau bentuk lain seperti hadiah berupa benda yang memiliki nilai yang bergengsi.

\section{Peran Peserta Didik}

Peserta didik adalah suatu objek yang harus diarahkan dan diubah khususnya yang berkaitan dengan perilaku (McLeod, 2011). Sebagai objek yang diajar dan diarahkan, peserta didik mempunyai peran sebagai berikut:

a. Melaksanakan tugas sesuai dengan instruksi dan petunjuk-petunjuk yang diberikan.

b. Jika tugas yang diberikan guru dikerjakan dengan baik sesuai dengan standar yang diinginkan, peserta didik akan menerima ganjaran yang baik, tetapi jika tidak dapat menyelesaikan tugas dengan baik, maka akan menerima hukuman sebagai konsekuensi terhadap pekerjaan yang dilakukan.

\section{Peran Media dan Teknologi}

Media dan teknologi dapat digunakan untuk menunjang proses pembelajaran mencakup media dalam bentuk teks, audio, video, dan komputer yang mengintegrasikan perangkat lunak sebagai tutorial dalam menghasilkan tugas pembelajaran (Moore, 2011). Peran media dan teknologi dalam pembelajaran dapat diuraikan sebagai berikut:

a. Mengorganisasi berbagai bahan pembelajaran seperti teks, audio, video, dan latihan-latihan dalam program pembelajaran (Harasim, 2017).

b. Menyajikan bahan dengan menggunakan kartu flash untuk membantu peserta didik mendapatkan umpan balik secepatnya. Kartu flash terdiri atas dua sisi, sisi pertama berisi bahan atau sejumlah pertanyaan dan sisi kedua berisi jawaban. Ketika menggunakan kartu ini, satu sisi disajikan kepada peserta didik, setelah memberi respon peserta didik dapat membalikkan sisi lain dari kartu flash untuk melihat jawabannya (Jarvis, 2011).

c. Menyelesaikan tugas atau latihan dengan menggunakan program pembelajaran berbantukan komputer. Soal-soal dihimpun dalam suatu perangkat lunak (software) yang disesain untuk diselesaikan hanya dengan mengelik tombol A, B, C, atau $\mathrm{D}$ dengan menggunakan mouse. Setelah soal semuanya dijawab, skor secara otomatis akan keluar dan jika terjadi banyak kesalahan, peserta didik langsung dapat memeriksa kembali dengan jawaban yang benar dengan hanya mengelik tombol yang dibutuhkan (Dalsgaard, 2005).

d. Peserta didik dapat belajar mandiri dengan menggunakan kekuatan komputer (computer's power). Di dalam komputer disediakan bahan-bahan sederhana, latihan 
dan elemen-elemen yang dipraktikan yang dapat ditambahkan pada program lain berupa tutorial, simulasi, atau program untuk peyelesaian masalah sehingga peserta didik dapat diajarkan secara mandiri (Moore, 2011).

\section{Perspektif Kognitif}

Sebagai akibat dari beberapa keterbatasan perspektif yang dikembangkan oleh kaum behavioris, perspektif belajar kognitif justru memberikan tanggapan langsung bahwa belajar bukan hanya dapat diamati melalui perubahan perilaku, melainkan juga perubahan struktur mental internal seseorang yang memberikan kapasitas padanya untuk menunjukkan perubahan perilaku (Porcaro, 2011). Struktur mental yang dimaksud mencakup pengetahuan, keyakinan, keterampilan, harapan, dan mekanisme lainnya dalam otak manusia.

\section{Definisi Belajar dalam Perspektif Kognitif}

Untuk memahami makna belajar menurut perspektif kognitif, sebaiknya dilihat berdasarkan tiga teori yang berkembang, yakni teori medan (Cognitive field theory), teori skema, dan teori information-processing theory. Teori medan mengatakan bahwa yang dimaksud dengan belajar adalah proses mental yang terjadi dalam individu yang saling terkait secara dinamis dengan perilaku. Proses mental tersebut memengaruhi motivasi baik berupa motivasi eksternal maupun motivasi internal yang kemudian berdampak pada perubahan perilaku (Olson, 2015: 284).

Kedua, teori schema, beranggapan bahwa schema yang telah menjadi bagian yang sudah terbentuk dalam diri anak akan berguna dalam mengingat pengalaman yang diperoleh melalui beberapa proses seperti menyeleksi, mengambil intisari, dan menginterpretasi yang kemudian dapat dimodifikasi melalui aktivitas yang merujuk pada penambahan, penyesuaian, dan restrukturisasi (Sherwood \& Lee, 2003).

Ketiga, information-processing theory menjelaskan bahwa belajar adalah suatu upaya untuk memproses, memperoleh, dan menyimpaninformasi melalui memory jangka pendek (short term memory), dan memori jangka panjang (long term memory). Singkatnya, belajar menurut teori ini adalah suatu perubahan pengetahuan yang tersimpan di dalam memori (Newby et al., 2011: 30). Dikatakan belajar ketika seseorang mampu mengumpulkan dan menyimpan informasi sebanyak-banyaknya di dalam tempat penyimpanan. Dengan demikian, ketiga teori ini bersandar pada aspek kognisi menyangkut proses mental dan memori dalam menginput dan memanggil kembali informasi yang pernah disimpan.

\section{Proses Belajar}

Perspektif kognitif memandang proses belajar sebagai suatu bentuk pengaktifan memori. Memori dipandang bukan hanya sekadar menerima informasi, melainkan juga mensitesis, mengorganisasi, dan mengintegrasikan (teori medan) dengan pengetahuan yang telah tersimpan di dalam memori agar menjadi skema atau kebiasaan (teori skema). Proses belajar dalam perspektif kognitif melibatkan tiga proses; perhatian, pengodean, dan pemanggilan kembali informasi (teori proses kognisi)(Simon, 
1978). Perhatian (attention) merujuk pada proses pengambilan informasi dari lingkungan dan mengabaikan informasi yang lain. Artinya, memfokuskan diri pada suatu sumber informasi. Pengodean (encoding) adalah proses penerjemahan informasi ke dalam bentuk yang dapat berarti dan dapat diingat kembali. Pemanggilan kembali (retrieval) merujuk pada proses mengingat kembali informasi untuk tujuan khusus (Cegielski, Allison Jones-Farmer, Wu, \& Hazen, 2012). Belajar baru bisa terjadi ketika individu-individu mengode informasi dengan cara yang memudahkan mereka untuk mengingat informasi yang tersimpan dalam memori, kemudian menggunakannya dalam suatu situasi khusus.

\section{Peranan Pendidik}

Secara umum pendidik perperan dalam mengaktifkan proses kognisi peserta didik dalam menginput informasi, membuat keterkaitan antara informasi yang diperoleh sebelumnya dengan informasi pada saat mereka belajar, dan menerjemahkan informasi tersebut dalam bentuk yang mudah dipahami dan digunakan dalam suatu situasi tertentu. Secara khusus pendidik berperan dalam hal-hal sebagai berikut:

a. Mengorganisasi informasi atau konten yang diajarkan kepada peserta didik. Peserta didik secara aktif mencari informasi untuk dapat dipahami, dan informasi baru akan mudah dikode jika telah diorganisasi dengan baik (Hockey, Gaillard, \& Coles, 2012).

b. Membuat hubungan, rentetan, dan korelasi antara informasi baru dengan peristiwa sebelumnya. Ketersambungan informasi dapat memudahkan peserta didik untuk menyimpan, memanggil kembali, dan mengintegrasikan dalam suatu situasi di mana saja mereka berada. Ketersambungan informasi ini juga membuat peserta didik mampu memprediksi berbagai peristiwa yang kemudian terjadi dengan mempelajari kode-kode yang ada (Rudolph \& Popp, 2007).

c. Menggunakan berbagai alat bantu penguat memori seperti menggaris bawahi, membuat iktisar, pola-pola, alat bantu menghafal (mnemonics), analogi, perumpamaan, dan perbandingan. Selain itu, pendidik dapat menciptakan suatu teknik lain yang dapat mendorong peserta didik untuk memerhatikan informasi penting, membuat kode, dan mampu mengingat kembali informasi yang tersimpan di dalam memori (Lachman, Lachman, \& Butterfield, 2015).

\section{Peran Peserta Didik}

Proses pembelajaran dalam perspektif kognitif melibatkan pendidik untuk mendesain, mengorganisasi, dan membuat hubungan informasi. Hal ini bukan berarti peserta didik hadir secara pasif hanya dengan menyerahkan sepenuhkan kepada pendidik. Tetapi, peserta didik dapat melakukan berbagai aktivitas yang dapat mengolah kognisi secara aktif. Adapun tanggungjawab peserta didik dapat dijelaskan sebagai berikut:

a. Memetakan informasi dengan membuat pemetaan ide dan mengorganisasinya agar dapat diinput dan disimpan di dalam memori jangka panjang. 
b. Membentuk jaringan informasi untuk menghubungkan informasi yang sedang dipelajari dengan yang tersimpan dalam memori.

c. Menyimpan dan menghafal informasi dengan menggunakan kode-kode sebagai penanda yang membedakan informasi atau konten yang satu dengan konten yang lainnya.

\section{Peran Media dan Teknologi}

Pada pembahasan sebelumnya telah diuraikan bahwa perspektif kognitif mengakomodasi pengaktifan proses memori sebagai indikator belajar. Dalam hubungannya dengan peran media dan teknologi, perspektif kognitif memandang bahwa belajar akan dapat dilakukan dengan mudah jika memaksimalkan peran teknologi untuk memfasilitasi proses kognitif termasuk mengorganisasi, menyebarkan, menghubungkan, mengasimilasi, dan mengakomodasi informasi bari dalam memori (Vaishnavi \& Kuechler, 2015). Secara khusus, media dan teknologi dapat digunakan untuk:

a. Memetakan sejumlah informasi yang banyak dan meletakannya dalam bentuk ikhtisar yang berguna bagi peserta didik. Salah satu perangkat lunak (software) yang cocok untuk melakukan pemetaan ide adalah inspiration, yang dapat diunduh secara gratis melalui Internet (Siemens, 2014).

b. Mengumpulkan, menyeleksi, dan menggunakan informasi melalui jaringan (website). Berbagai situs dapat diakses untuk mencari dan memberi penguatan informasi. Integrasi situs-situs online dan informasi yang diperoleh secara langsung melalui sumber-sumber teks dapat membantu peserta didik untuk menyimpannya di dalam memori jangka panjang (Koehler, Mishra, \& Cain, 2013).

c. Memvisualisasi data dan informasi dengan menggunakan program spreadsheet baik dalam bentuk bagan, gambar, maupun dalam bentuk tabel yang memudahkan peserta didik untuk menginput informasi secara cepat (Vaishnavi \& Kuechler, 2015).

d. Menghubungkan informasi baru dengan pengetahuan dan pengalaman yang pernah dilakukan sebelumnya dengan menggunakan multimedia, yang menggabungkan unsur-unsur teks, suara, dan benda bergerak dapat membantu peserta didik dalam mengenal informasi baru dan informasi sebelumnya dengan bermakna (Siemens, 2014).

\section{Perspektif Konstruktivis}

Jika perspektif behavioris memandang belajar sebagai perubahan prilaku yang dapat diamati dan perspektif kognitif memberi penekanan pada perubahan proses mental, maka perspektif konstruktivis mendefinisikan belajar sebagai proses konstruksi pengetahuan oleh peserta didik berdasarkan pengalaman yang telah dilalui. Artinya, belajar bukan hanya diperoleh melalui hubungan antara peserta didik dengan pendidik atau hubungan timbal balik antara pendidik dan peserta didik, melainkan lebih dari itu, yakni dapat pula dilakukan dengan mengkonstruksi pengetahuan melalui pengalaman belajar dengan pendidik, peserta didik, dan berbagai sumber belajar lainnya (Eggen \& Kauchak, 2007). 
Perspektif konstruktivis mengutamakan keaktifan peserta didik dalam mengkonstruksi pengetahuan berdasarkan interaksi dengan dunia nyata atau pengalaman belajar yang difasilitasi oleh pendidik. Pembelajaran berbasis konstruktivis memandang peserta didik dan proses belajar menjadi fokus utama, sedangkan pendidik berperan sebagai fasilitator, dan atau bersama-sama peserta didik juga terlibat dalam proses belajar, proses konstruksi pengetahuan. Konstruktivis merupakan kumpulan teori termasuk pembelajaran generatif (generative learning), discovery learning, dan situated learning (Newby et al., 2011). Ide yang paling terkenal dari teori konstruktivis adalah individu secara aktif mengonstruksi pengetahuan melalui bekerja untuk menyelesaikan persoalan realistik dengan berkolaborasi dengan yang lain.

\section{Definisi Belajar dalam Perspektif Konstruktivis}

Perspektif kognitif memandang belajar dengan menekankan pada pengetahuan. Teori ini memandang pengetahuan sebagai representasi objektif dari pengalaman. Sedangkan perspektif konstruktivis mendefinisikan pengetahuan sebagai interpretasi subjektif terhadap pengalaman (Harasim, 2017). Artinya, dalam pandangan Information Processing, pikiran (mind) diumpamakan seperti cermin yang merefleksikan secara akurat tentang objek atau peristiwa melalui pengalaman. Asumsinya bahwa pengetahuan adalah objektif dan dapat dideskripsikan secara terpisah dari yang mengetahui pengetahuan tersebut. Dengan kata lain, tanpa memerhatikan cerminnya siapa yang digunakan itu, tetapi gambar yang terdapat di dalam cermin tersebut pada dasarnya sama saja. Dengan demikian, belajar dalam pandangan teori information processing merujuk pada pemerolehan representasi pengetahuan baru.

Sebaliknya dalam pandangan konstruktivis, pikiran diibaratkan lensa. Jika kita melihat melalui lensa kita, beberapa aspek dari pengalaman kita berada tepat pada titik fokus, beberapa yang lain kelihatan kabur, dan yang lainnya lagi tidak kelihatan sama sekali. Asumsi dari pandangan konstruktivis bahwa pengetahuan tidak dapat dipisah dari yang mengetahui pengetahuan tersebut. Artinya, gambar yang kita lihat ditentukan oleh lensa yang kita gunakan sehingga belajar merujuk pada konstruksi interpretasi baru (Newby et al., 2011). Oleh karena itu, konstruksi pengetahuan adalah suatu proses memikirkan dan menginterpretasi pengalaman. Mengingat setiap individu masing-masing memiliki keunikan pengalaman dilihat dari lensa yang unik, maka setiap individu tersebut mengonstruk pengetahuan yang unik pula. Di sinilah perlunya belajar dalam konteks sosial agar individu yang satu dapat berkolaborasi dengan yang lainnya dalam membangun makna dan menginterpretasi pengetahuan melalui pengalaman termasuk dalam berinteraksi dengan individu lainnya.

\section{Proses Belajar}

Proses belajar dalam perspektif konstruktivis didasari oleh suatu premis yang mengatakan bahwa pengetahuan dikonstruksi di mana peserta didik mencoba membangun makna dari setiap pengalaman yang mereka lakukan (Gould \& Taylor, 2017). Proses belajar dapat diuraikan sebagai berikut:

a. Kegiatan yang terus-menerus dilakukan dengan cara menginterpretasi dan merefleksi pengalaman (Karagiorgi \& Symeou, 2005). 
b. Melakukan aktivitas dalam menciptakan, mengetes, dan menyeleksi model mental untuk mengevaluasi pengalaman. Semakin banyak pengalaman seseorang, semakin cepat berkembang, dan semakin kaya pula model mental yang dimiliki karena mampu menggabungkan antara makna yang dibuat dengan sejumlah pengalaman yang dialami (Wu, Hsiao, Wu, Lin, \& Huang, 2012).

c. Konstruksi pengetahuan terjadi dari interpretasi pengalaman baik dikembangkan secara individu maupun hasil bagi (sharing) melalui interaksi sosial (Cobern, 1993).

\section{Peran Pendidi}

Secara umum, tanggung jawab pendidik dalam menerapkan pembelajaran konstruktivis adalah untuk menciptakan dan memelihara lingkungan belajar dalam konteks dan berorientasi kolaboratif. Dengan demikian peran pendidik dalam menerapkan pembelajaran konstruktivis dapat dijabarkan sebagai berikut:

a. Mempersiapkan kesempatan untuk menyelesaikan masalah-masalah yang realistik dan berarti dan merefleksi pengalaman-pengalaman dalam penyelesaian masalah tersebut. Masalah-masalah yang diintegrasikan ke dalam pembelajaran harus (1) dilihat oleh peserta didik untuk menilai aspek kemenarikan dan relevansi, (2) realistik, melibatkan peserta didik untuk menggunakan dan menerapkan pengetahuan mereka (Dalsgaard, 2005).

b. Mempersiapkan aktivitas kelompok belajar untuk saling berinteraksi dalam membagi (sharing) pengalaman. Peserta didik belajar melalui interaksi dengan yang lain. Mereka bekerja secara kolaborasi, saling mengajar satu sama lain (peer teaching), membentuk tim kerja (team work), dan saling menukar pandangan (exchange ideas) untuk menyelesaikan masalah yang dihadapi (Mayo, 2010).

c. Mengarahkan, mencontohkan dan memfasilitasi proses mengonstruksi pengetahuan dalam konteks saling memecahkan masalah (Goldin, 1990).

\section{Peran Peserta didik}

Peserta didik dalam perspektif konstruktivis berperan secara aktif untuk menyelesaikan masalah-masalah baik dilakukan secara individu maupun melibatkan pihak lain termasuk belajar dengan mengobservasi atau mengamati pengalaman orang lain secara nyata (Harasim, 2017). Peserta didik bertanggungjawab untuk melakukan hal-hal sebagai berikut:

a. Menentukan kebutuhan pembelajaran, merumuskan tujuan pembelajaran, dan memonitori perkembangannya sendiri.

b. Melibatkan diri secara aktif dalam berinteraksi dengan peserta didik lain, dengan pendidik, dan sumber belajar.

c. Mengeksplorasi, mengkaji, dan menemukan sendiri pengetahuan yang dikonstruksi dari pengalaman belajar baik dilakukan secara individu maupun dilakukan secara kolaborasi dengan peserta didik yang lain.

\section{Peran Teknologi dan Media}

Peran media dan teknologi dalam pembelajaran konstruktivis adalah memfasili- 
tasi terbentuknya interaksi secara kolaboratif dan membangun makna dalam konteks yang lebih dapat dipahami secara bermakna. Secara perinci media dan teknologi dapat diarahkan untuk:

a. Membangun jaringan komunikasi kolaboratif antara peserta didik, dosen, guru, atau instruktur, dan sumber belajar. Beberapa software online yang dapat digunakan untuk telekonferensi adalah skype, yahoo messenger, face book video conference, dan jaringan line yang digunakan secara sinkronus (synchronous) dan email, mailing list, web-blog untuk komunikasi asinkronus (asyncronous) (Gould \& Taylor, 2017).

b. Menyediakan berbagai lingkungan penyelesaian masalah yang kompleks, realistik, dan aman. Teknologi yang dapat digunakan untuk menyediakan lingkungan yang nyaman adalah hypermedia dan software yang dapat digunakan untuk menciptakan projek(Koehler et al., 2013).

c. Membangun dan menciptakan makna secara aktif melalui Internet untuk mencari riset-riset mutakhir, foto-foto, video. Hal ini dapat membantu peserta didik bukan hanya sekadar menikmati penelusuran itu, melainkan juga dapat belajar dan memelihara apa yang dipelajarinya (Mayo, 2010).

Setelah menjabarkan tiga perspektif belajar dilihat dari definisi belajar, proses belajar, peran pendidik dan tanggungjawab peserta didik, serta peran media dan teknologi dalam mengembangkan pengetahuan, sikap, dan keterampilan peserta didik, maka berikut ini diilustrasikan ringkasan pembahasan seperti dalam tabel berikut.

Tabel 1. Ringkasan Perspektif Belajar

\begin{tabular}{|c|c|c|c|}
\hline \multirow{2}{*}{ ASPEK } & \multicolumn{3}{|c|}{ PERSPEKTIF } \\
\hline & Behavioris & Kognitif & Konstruktivis \\
\hline Definisi Belajar & $\begin{array}{l}\text { Perubahan } \\
\text { perilaku sebagai } \\
\text { akibat dari } \\
\text { interaksi antara } \\
\text { stimulus dan } \\
\text { respon }\end{array}$ & $\begin{array}{l}\text { Perubahan dalam } \\
\text { pengetahuan yang } \\
\text { tersimpan di dalam } \\
\text { memori }\end{array}$ & $\begin{array}{l}\text { Perubahan dalam } \\
\text { pemaknaan yang } \\
\text { dikonstruksi melalui } \\
\text { pengalaman }\end{array}$ \\
\hline Proses Belajar & $\begin{array}{l}\text { Anteseden } \rightarrow \\
\text { Perilaku } \rightarrow \\
\text { Konsekuensi }\end{array}$ & $\begin{array}{l}\text { Perhatian } \rightarrow \\
\text { Pengodean } \rightarrow \\
\text { mengingat informasi } \\
\text { dari memori }\end{array}$ & $\begin{array}{l}\text { Proses pengalaman } \\
\text { yang terus-menerus } \\
\text { dan refleksi yang } \\
\text { dilakukan dalam } \\
\text { kelompok }\end{array}$ \\
\hline $\begin{array}{l}\text { Peran } \\
\text { Pendidik } \\
\text { (Guru, Dosen, } \\
\text { Instruktur) }\end{array}$ & $\begin{array}{l}\text { - Merumuskan } \\
\text { tujuan } \\
\text { - Mengarahkan } \\
\text { perilaku dengan } \\
\text { contoh-contoh }\end{array}$ & $\begin{array}{l}\text { - Mengorganisasi } \\
\text { informasi baru } \\
\text { - Menghubungkan } \\
\text { informasi baru } \\
\text { dengan } \\
\text { pengetahuan } \\
\text { yang sudah ada } \\
\text { - Menggunakan } \\
\text { berbagai }\end{array}$ & $\begin{array}{l}\text { - Mempersiapkan } \\
\text { kesempatan untuk } \\
\text { menyelesaikan } \\
\text { masalah yang } \\
\text { realistik dan } \\
\text { bermakna, serta } \\
\text { merefleksikan } \\
\text { pengalaman } \\
\text { - Mempersiapkan }\end{array}$ \\
\hline
\end{tabular}




\begin{tabular}{|c|c|c|c|}
\hline & & $\begin{array}{l}\text { perhatian, } \\
\text { pengodean, dan } \\
\text { contoh-contoh }\end{array}$ & $\begin{array}{l}\text { kegiatan belajar } \\
\text { kelompok } \\
\text { - Mengarahkan dan } \\
\text { mencontohkan } \\
\text { proses } \\
\text { mengonstruksi } \\
\text { makna dalam } \\
\text { konteks saling } \\
\text { menyelesaikan } \\
\text { masalah }\end{array}$ \\
\hline $\begin{array}{l}\text { Peran peserta } \\
\text { didik }\end{array}$ & $\begin{array}{l}\text { Merespon contoh- } \\
\text { contoh }\end{array}$ & $\begin{array}{l}\text { Melakukan sintesis } \\
\text { informasi secara } \\
\text { aktif }\end{array}$ & $\begin{array}{l}\text { Mengeksplorasi } \\
\text { seperti seorang } \\
\text { ilmuan }\end{array}$ \\
\hline $\begin{array}{l}\text { Peran } \\
\text { teknologi }\end{array}$ & $\begin{array}{l}\text { Mengorganisasi } \\
\text { berbagai macam } \\
\text { bahan (teks, audio, } \\
\text { video) dan latihan- } \\
\text { latihan ke dalam } \\
\text { program } \\
\text { pembelajaran }\end{array}$ & $\begin{array}{l}\text { Membantu peserta } \\
\text { didik } \\
\text { mengorganisasi } \\
\text { informasi baru, } \\
\text { menghubungkannya } \\
\text { dengan } \\
\text { pengetahuan yang } \\
\text { sudah ada, dan } \\
\text { mengode ke dalam } \\
\text { memori }\end{array}$ & $\begin{array}{l}\text { - Memfasilitasi } \\
\text { komunikasi } \\
\text { kolaboratif antara } \\
\text { peserta didik, } \\
\text { instruktur, dan } \\
\text { ahli lainnya } \\
\text { - Mempersiapkan } \\
\text { berbagai } \\
\text { lingkungan yang } \\
\text { kompleks, } \\
\text { realistik, dan } \\
\text { aman. }\end{array}$ \\
\hline
\end{tabular}

\section{PENUTUP}

Secara umum, perspektif dimaknai sebagai cara memandang sesuatu. Terdapat tiga perspektif yang sering dikaji dalam teori belajar, yaitu behavioris, kognitivis, dan konstruktivis. Definisi belajar berbeda-beda sesuai dengan masing-masing perspektif. Dalam pandangan behavioris, belajar adalah perubahan perilaku sebagai akibat dari interaksi antara stimulus dan respon. Perspektif ini menggunakan tiga pendekatan yaitu classical conditioning, Connectionism, dan operant conditioning. Pertama, menekankan pada reaksi gerak reflek setelah menerima stimulus dari luar. Kedua, menekankan pada jaringan asosiasi atau hubungan antara stimulus dan respon. Ketiga menekankan pada sejauh mana konsekuensi yang ditimbulkan.

Perspektif kognitif memandang belajar merupakan proses mental yang terjadi dalam individu yang saling terkait secara dinamis dengan perilaku. Perspektif ini mengatakan bahwa proses belajar sebagai suatu bentuk pengaktifan memori. Pandangan konstruktivis tentang belajar bahwa individu secara aktif mengonstruksi pengetahuan melalui bekerja untuk menyelesaikan persoalan realistik dengan berkolaborasi dengan yang lain. Perspektif konstruktivis tentang pengetahuan sebagai interpretasi subjektif terhadap pengalaman. 
Perspektif belajar behavoris memberi penekanan pada pengembangan media dan teknologi untuk mengorganisasi,menyajikan bahan dan sumber, menyelesaikan tugas dan belajar mandiri dengan alat bantu komputer. Perspektif kognitif memberi penekanan pada pemetaan sujumlah informasi dan memanfaatkan jaringan untuk penguatan dalam memproses informasi. Perspektif konstruktivis memberi penekanan pada membangun jaringan komunikasi kolaboratif dengan memanfaatkan social media baik secara asingkronus maupun singkronus, menyediakan tempat dan ruang secara virtual untuk memanfaatkan teknologi mutakhir untuk mengonstruksi makna berdasarkan pengalaman.

\section{DAFTARPUSTAKA}

Bates, A. W., \& Poole, G. (2003). Effective Teaching with Technology in Higher Education: Foundations for Success. ERIC.

Brush, F. R. (2014). Aversive conditioning and learning. Academic Press.

Cegielski, C. G., Allison J, L., Wu, Y., \& Hazen, B. T. (2012). Adoption of cloud computing technologies in supply chains: An organizational information processing theory approach. The International Journal of Logistics Management, 23(2), 184-211.

Clark, R. C., \& Mayer, R. E. (2008). Learning by viewing versus learning by doing: Evidencebased guidelines for principled learning environments. Performance Improvement, 47(9), 513.

Cobern, W. W. (1993). Contextual constructivism: The impact of culture on the learning and teaching of science. In The practice of constructivism in science education (pp. 51-69). Lawrence Erlbaum.

Dalsgaard, C. (2005). Pedagogical quality in e-learning: Designing e-learning from a learning theoretical approach. E-Learning and Education.

Driscoll, M. P., \& Driscoll, M. P. (2005). Psychology of learning for instruction.

Eggen, P. D., \& Kauchak, D. P. (2007). Educational psychology: Windows on classrooms. Prentice Hall.

Gagne, R. M., Wager, W. W., Golas, K. C., Keller, J. M., \& Russell, J. D. (2005). Principles of instructional design. Performance Improvement, 44(2), 44-46.

Goldin, G. A. (1990). Chapter 3: Epistemology, constructivism, and discovery learning in mathematics. Journal for Research in Mathematics Education. Monograph, 4, 31-210.

Gould, N., \& Taylor, I. (2017). Reflective learning for social work: research, theory and practice. Routledge.

Gredler, M. E. (2009). Learning and instruction: Theory into practice. New Jersey: Prentice Hall.

Harasim, L. (2017). Learning theory and online technologies. Taylor \& Francis.

Hockey, G. M., Gaillard, A. W. K., \& Coles, M. G. H. (2012). Energetics and human information processing (Vol. 31). Springer Science \& Business Media.

Hutchison, E. D., \& Charlesworth, L. W. (2003). Theoretical perspectives on human behavior. Hutchison (Ed.), Dimensions of Human Behavior: Person and Environment, 2, 46-88.

Jarvis, P. (2011). Paradoxes of learning: On becoming an individual in society (Vol. 80). Routledge.

Karagiorgi, Y., \& Symeou, L. (2005). Translating constructivism into instructional design: Potential and limitations. Journal of Educational Technology \& Society, 8(1).

Koehler, M. J., Mishra, P., \& Cain, W. (2013). What is technological pedagogical content knowledge (TPACK)? Journal of Education, 13-19.

Lachman, R., Lachman, J. L., \& Butterfield, E. C. (2015). Cognitive psychology and information 
processing: An introduction. Psychology Press.

Lever-Duffy, J., McDonald, J., \& Mizell, A. (2015). Teaching and Learning with Technology. New York: Pearson Education Inc.

Mayo, J. A. (2010). The epistemological roots of constructivism. American Psychological Association.

McLeod, S. A. (2011). Bandura-social learning theory. Retrieved from.

Mooney, L., Knox, D., \& Schacht, C. (2014). Understanding social problems. Nelson Education.

Moore, J. (2011). Behaviorism. The Psychological Record, 61(3), 449.

Newby, T. J., Stepich, D. A., Russell, J. D., \& Lehman, J. D. (2011). Educational technology for teaching and learning. Prentice Hall.

Olson, M. H. (2015). An introduction to theories of learning. Psychology Press.

Ormrod, J. E. (2011). Human learning. Pearson Higher Ed.

Payne, M. (1998). Social work theories and reflective practice. In Social Work (pp. 119-137). Springer.

Peppler, K. A., \& Kafai, Y. B. (2007). From SuperGoo to Scratch: Exploring creative digital media production in informal learning. Learning, Media and Technology, 32(2), 149-166.

Porcaro, D. (2011). Applying constructivism in instructivist learning cultures. Multicultural Education \& Technology Journal, 5(1), 39-54.

Rudolph, T. J., \& Popp, E. (2007). An information processing theory of ambivalence. Political Psychology, 28(5), 563-585.

Santrock, J. W. (2011). A topical approach to life-span development. McGraw-Hill.

Sherwood, D. E., \& Lee, T. D. (2003). Schema theory: critical review and implications for the role of cognition in a new theory of motor learning. Research Quarterly for Exercise and Sport, 74(4), 376-382.

Siemens, G. (2014). Connectivism: A learning theory for the digital age.

Simon, H. A. (1978). Information-processing theory of human problem solving. Handbook of Learning and Cognitive Processes, 5, 271-295.

Storey, G. A. (2006). Theory and Practice of Perspective. Courier Corporation.

Vaishnavi, V. K., \& Kuechler, W. (2015). Design science research methods and patterns: innovating information and communication technology. Crc Press.

Woolfolk, A. E. (2009). Educational psychology. Needham Heights, MA, US: Allyn \& Bacon.

Wu, W., Hsiao, H., Wu, P., Lin, C., \& Huang, S. (2012). Investigating the learning-theory foundations of game-based learning: a meta-analysis. Journal of Computer Assisted Learning, 28(3), 265-279.

Yaumi, M. (2016). Prinsip-Prinsip Desain Pembelajaran Disesuaikan dengan Kurikulum 2013 (Edisi Kedua). Jakarta: Kencana.

Zimmerman, B. J., \& Schunk, D. H. (2008). An essential dimension of self-regulated learning. Motivation and Self-Regulated Learning: Theory, Research, and Applications, 1. 